\title{
PULMONARY EMPHYSEMA AND ASSOCIATED PROBLEMS \\ IN ANAESTHESIA. A REVIEW
}

\section{E. N. Hughes, MI.D, and R. E. Simpson, M.D. ${ }^{1}$}

Eגrphysema is a word which has been derived from the Greek prefix "en" which means "in" and the noun "physema" which means "a blowing." The number of adjectives which have been used to qualify emphysema is atmost beyond count and yet there are only two definitions of this word in the correct pathological sense The first of these denotes the presence of arr in the interstices of the connective trssue of a part The second refers to the dilatation of the pulmonary arr vesicles, usually through atrophy of the septa between alveoll. It is with the latter of these concepts that this discussion is concerned.

It has been stated by Carter (1) and his group that pulmonary emphysema is the most common, the most disabling, and the most progressive of all respiratory diseases seen in general hospitals.

Emphysema has been termed the opposite of atelectasis (2). A pathological account of the fully developed process will describe the lungs as voluminous, pale, and dry with a soft feathery feel, and showing pitting on pressure. The pitting is due to loss of elastic tissue and not to oedema. Bullae and blebs may be present in the periphery especially on the surface, but particularly where there is least support, in the regions of the apex, the base, and along the anterior margins The lung may expand to he in front of the heart, and obliterate the area of superficial cardıac dullness

Under the clinical microscope a section of emphysematous lung parenchyma presents a delicate structure like torn lace. The arr vesicles are greatly reduced in number, but increased in size. The broken septa show loss of elastic tissue and relative avascularity. Where vessels do appear they have been narrowed if not obliterated. The avascularity produces the pale, dry lung and also obstructs the pulmonary circulation. The alveolar changes have been produced by the contmuous increased intra-alveolar pressure of chronic coughing. The chromic coughing is usually a manufestation of incomplete bronchial obstruction and may follow any of the common causes of obstruction. A non-obstructive form of the disease does occur but is much less severe and respiratory physiology is usually much less altered.

The repercussions of chronic pulmonary emphysema are felt throughout the entire body and are usually of grave consequence, but only the most advanced cases could be expected to show all of the pathological features of this disease. The bony thorax is expandecl, the rabs raised, and the sternum is pushed forward so that the chest loses its ovord contour and becomes rounded with equal anteroposterior and lateral diameters. Often the costal cartilages become calcified and thus the chest becomes fixed in this expanded attitude The percussion $\backslash$ note is everywhere hyper-resonant, and superficial cardiac dullness obliterated Respiratory movements are diminished and the patient experiences great difficulty with

1Department of Anesthesiology, Shaughnessy Veteran's Hospital, and University of British Columbia, Vancouver, B C 
expiration, which is prolonged Pulmonary systolic jressure is increased by obstruction at the alveolar level where the alveolar anc septal vessels are largely non-existent or partly obliterated. The increased pulmonary pressure eventually results in hypertrophy and dilatation of the right ventricle The venous congestion then becomes generalized throughout the body. Dyspnoea with cyanosis develops with compensatory polycythemia and the latter only aggravates the alterations in cardio-pulmonary physiology A spontaneous pneumothorax can occur from rupture of a bulla into the pleural cavity (2).

The surgical risk is especially great in the patient with a chronic respiratory disease (3). The anaesthesiologist should be well versed in the fundamentals of the patho-physiology in these cases and this requires a foundation in normal pulmonary phyșology. Increasing numbers of respuratory cripples are coming to surgery for both mandatory and elective surgical procedures This obviously reflects progress not only in surgical technique but also in anaesthesiology and internal medicine, and is partly due to the discovery of antibiotics and a better understanding of the water and salt balance. [n short, the success with these patients has been the result of a better integration of preoperative, operative, and postoperative management of the patient

\section{Classification of the Types of Pulironary Emphysema}

In the past confusion has arisen in medical literature over the classification of the types of pulmonary emphysema Segal and Dulfano (4) in a monograph on pulmonary emphysema published in 1953 classified the types as (A) obstructive. (1) chronic pulmonary emphysema, (2) acute bullous emphysema, (B) non-obstructive: (1) senile emphysema, (2) compensatory emphysema Senle emphysema, often called atrophic emphysema, or sometımes postural emphysema, is commonly associated with wasting diseases There is no alveolar distension, no lung enlargement and no bullae appear on the surface The microscope shows atrophy with broken septa between alveolı and the formation of large spaces. The atrophy is the result of defective nutrition and according to Boyd should not be called emphysema (2)

Compensatory emphysema is exactly what the term implies A segment of a lung compensates for the loss of an adjacent lung segment or for the loss of an entire lobe or for the loss of the entre opposite lung This most commonly follows surgical resections, atelectasis, fibrosis or compression

Acute bullous emphysema, again as the name implies, is rapid in onset It has been called vesicular emphysema. It is most commonly seen in children as a terminal complication of asphyxia from acute bronchial obstruction in such diseases as influenza, acute tracheo-bronchitss (and can follow measles), pertussis and broncho-pneumonia It also occurs in patients asphyxiated from noxious irritants, gases and drowning It has been termed the "effort lung" and with vigorous management as for respiratory insufficiency (29) may be reversible in whole or in part.

The chronic disabling obstructive form of pulmonary emphysema, the one most often seen in the middle-aged male and the one which concerns us here, is 
called chronıc pulmonary emphysema. It is also called "hypertrophıc," "eșsential," "respiratory," "functional," or "obstructive" emphysema, but these terms are superfluous. The disease is most commonly the result of chronic bronchits but can occur as a complication of almost any chronic pulmonary disorder. Segal and Dulfano (4) describe chronic pulmonary emphysema as diffuse, progressive, obstructive and hypoxic. If disabling or crippling is added, the picture is complete

It is axiomatic that the anaesthetist is primarily concerned with the chronic pulmonary type of emphysema However, it is the degree of pulmonary dystunction or altered respuratory. physiology which is his chief concern and thus he may encounter all types at various tumes (21). If he can be fore-armed with accurate laboratory data concerning the "respuratory potentral" or the efficiency of the respiratory membrane of his patient, he will be much better equipped to conduct a safer anaesthetic suited to the individual patient. It becomes necessary at this juncture to review some aspects of pulmonary function and pulmonary function tests

\section{Pulmionary Function Tests}

In the last ten to fifteen years a large number of physiological tests have been devised for the qualitative and quantitative estımation of pulmonary function $(19,20)$ These have now assumed equal importance with the tests of liver and renal function, but they indicate only how disease ras altered function, a dragnosis cannot be madé from therr evidence alone Less severe pathological conditions of the lungs (tuberculous cavities, cysts, and carcinomatous nodules, etc.) are very common, and if they do not alter function, then all results from the tests will obviously be normal

No single test of pulmonary function is of any real value when considered alone The primary function of the lung is gas exchange which although a single function involves a number of processes on which the pulmonary function tests are based (5)

A Ventilation

(1) Volume of air ventılating alveoli (must be adequate per unit of time)

(2) Distribution of arr ventilating alveolı (must be even)

B Diffusion (involves passage of oxygen and carbon dioxide across the alveolar capillary membranes)

C Pulmonary capillary blood flow

(1) Volume (must be adequate per unit of trme)

(2) Distribution (must be even to all ventrlated alveoli)

D Mechanical factors. in ventilation (measurement of the work involved or energy expended in arterializing the venous blood) (25).

Supplementary tests include arterial oxygen and carbon dioxide estimations and blood $\mathrm{pH}$

For many years the only tests of pulmonary function were the lung volumes But these are essentially anatornical measurements and therefore do not truly evaluate function. Even so, certain changes in lung volumes may be caused by alterations in physiological processes. 
In 1950 a group of American respiratory physiologists attempted to standardize the nomenclature with respect to lung volumes. They agreed to use the following terms and definitions $(5)$ :

\section{The Lung Volumes and Capacties}

A. Volumes. Theie are four primary volumes which do not overlap

(1) Tidal volume, or the depth of breathing, is the volume of gas inspned or expired during each respiratory cycle

(2) Inspiratory reserve volume (formerly complemeatal or complementary air minus tidal volume) is the maxima amount of gas that can be inspired from the end-inspiratory position

(3) Expiratory reserve volume (formerly reserve or supplemental air) is the maximal volume of gas that can be expired from the end-expiratory level

(4) Residial volume (formerly residual capacity or residual arr) is the volume of gas remaining in the lungs at the end of a maximal expiration

B Capacities There are four capacities, each of which includes two or more of the pumary volumes

(1) Total lung capactty (formerly total lung volume) is the amount of gas contaned in the lung at the end of a maximal inspiration

(2) Vital capacity is the maximal volume of gas that can be expelled from the lungs by forceful effort following a maximal inspiration

(3) Insprratory capacity (formerly complemertal or complementary arr) is the maximal volume of gas that can be inspired from the resting expiratory level

(4) Functional residual capacty (formerly functional resıdual air, equlibnum capacity, or mid-capacity) is the volume of gas remaining in the lungs at the resting, expiratory level The resting end-expiratory position is used here as a yase line because it vanes less than the end-inspiratory position

It is not within the scope of this paper to elucidate further the complexities in the performance of the tests of pulmonary function It is sufficient to point out what the more important individual tests are, what each is intended to measure, and how to interpret deviations from normal values as applied to chronic pulmonary emphysema

"Air remaining in the lung at the end of a maximal forced expiration is called residual air and this normally occupies about $25 \%$ of the total lung capacity (residual air plus vital capacity), being slightly smaller in the younger age group ( 20 per cent) and slightly larger in the older age group ( 30 per cent) If the volume of residual air occupies over 35 per cent of the total lung capacity a significant degree of pulmonary emphysema exists" (6). This last category divides thus: $35-45$ per cent indicates moderate degree of pulmonary emphysema; 45-55 per cent indicates advanced or severe degree of pulmonary emphysema; 55 per cent or higher indicates far advanced or very severe pulmonary emphysema (6).

Hyperinflation of the lungs is usually obvious on physical and X-ray examination In emphysema, because of hyperinflation, the total lung volume may become increased, but the increase in the ratio of the residual volume to the total lung capacity is more strikng This is due to an inablity to empty the lungs to a normal extent The vital capacity will depend on the residual volume, and the totál lung capacity may or may not be affected. Since the total lung 
capacity may be normal, increased, or decreased in the individual patient, it is the ratio residual aur . total lung capacity which is most significant. This corrects for changes in total lung volume and permits proper evaluation of the degree of emphysema. Residual cir can be measured quantitatively by means of the oxygen open circuit method. If the alveolar arr sample contains more than 15 per cent nitıogen after the patient has been breathing oxygen for seven minutes, the uniformity of air distribution in the lung is impaired.

However, a very recent and excellent article (3) states that there is only a fair correlation between the elevation of the ratio of residual volume to total lung capacity, and the severity of clinical symptoms. As this disease progresses, large blebs or bullae form which may have poor or no communication with the tracheo-bronchial system Thus, on physical or X-ray examination of the chest, the lungs may appear to be hyperinflated with large volumes, while the total lung capacity may be found to be small on physiological measurements.

Spirogram tracings offer rapid determinations of total ventilatory capacity, the timed vital capacity for three seconds and the maximal breathing capacity, and in addition give the shape of the exhalation curve. Total ventilatory capacty is a single volume measurement without respect to time and therefore has very httle value, and may be rassleading. The tume volume relation in vital capacity may be defined as the volume exhaled in the first second, or during the first three seconds, of the maximal expiratory effort Normal persons can exhale 83, 94 , and 97 per cent of their total vital capacity in one, two, and three seconds. The maximal breathing capacity by defintion is the maximum volume of air that can be moved by voluntary effort durng one minute Spirograms are simple and quick and permit satısfactory evaluation of changes in breathing resistance and the breathing reserve present in most patients. At the present time the most practical and satisfactory apparatus to obtain spirogran tracings is the large 13\%2-litre Collins respirometer (5).

Recently a single breath ventilatory test has been described (7). If the single breath provides an accurate estmmate of maximal expiratory velocity of air flow, the 05 -second expiratory capacity (E.C.), and at the same time provides a measure of maximal displaceable lung volume (T.V.C.), then this test is a concise but convenient method for preoperative evaluation of the anaesthetic risk as regards pulmonary ventılatory function. In less tharı 5 per cent of normal subjects the ratio, $05 \mathrm{sec}$ E.C. $\times 100 /$ T.V.C, was below 60 per cent. This value was selected as the lower limit of normal, and a reduction of this fraction below 60 per cent would indicate an obstructive ventilatory defect

Pulmonary emphysema further impaurs the function of the lungs by interfering with the process of gas exchange Uneven distribution of air to the alveoli in chronic pulmonary emphysema is brought about by bronchiolar narrowing, loss of elasticity, and presence of cysts, bullae, and blebs. The bronchiolar narrowing is a result of accumulated secretions, mural thickening, mucosal oedema, and bronchospasm. It has also been suggested that the circulation of the blood is uneven in the lung of the emphysematous patient and perfusion of poorly ventilated alveoli leads to arterial hypoxia and elevated partial pressure of carbon dioxide. 
Pulmonary ventlation is controlled by mechanisms intended to meet the metabolic and homeostatic needs of the body, and these mechanisms are largely reflex in nature.

The medullary respuratory centre responds to changes in arterial partial pressures of carbon dioxide, while the aortic and carotid bodies respond to arterial hypoxia The medullary centre is the more sensitive and affects the hyperventilation in the emphysematous patient at rest. With exercise both mechanisms are at work because of the additional increased hypoxia.

The development of respiratory acidosis is a constant threat and may be precipitated by pulmonary infection (without fever or leucocytosis) which in turn may precipitate cardiac fallure and acute hypoxia. In such cases oxygen therapy may be dangerous and may actually worsen respiratory acidosis in the following way The medullary centre becomes insensitive to the elevated partial pressure of carbon dioxide in the blood and ventilation depends upon aortic and carotıd body reflex stimulation-the so-called hypoxic drive As high concentrations of oxygen are given, these centres decrease their stımulation to respiration with further elevation of carbon dioxide. The $\mathrm{pH}$ of the blood falls and respiration is further depressed Mental confusion and even death may rèsult Death is hastened if respiratory depressants have been used (morphia, barbiturates and anaesthetic agents) If oxygen therapy is mandatory, it should be used with intermittent positive pressure breathing or mechanical respirators or following emergency pneumoperitoneum

The arterial blood $\mathrm{pH}$ is the best single test of the exact status of the acid-base balance and thus the presence of acidosis or alkalosis (6) Acidosis is a frequent problem in chronic pulmonary emphysema and often goes unrecognized. The carbon dioxide combining power cannot be relied upon to provide accurate information about acidosis or alkalosis in patients with enphysema.

The altered mechanics of breathing which occur with pulmonary emphysema interfere with the bellows function of the chest and can be explamed on a pathologic basis (3) (a) Bronchiolar obstruction mcreases the viscid and turbulent resistance to air movement and thus increases the work required in breathing. (b) Reduction in lung elasticity results in insufficient storage of elastic energy during inspiration to meet the needs of expration, and therefore muscular work is needed to expel air (c) Blebs, bullae, and cysts which may communicate poorly or not at all with air passages are resistant to deformation, restrictıng breathing and increasing the work of these movements. $(d)$ The position of hyperinflation reduces the mechanical advantage of the muscles of respiration (3).

There is a reduction in the normal action of the diaphragm and lower costal muscles with an increased activity of the upper costal and accessory muscles. Dyspnoea can result from an increase in the ventilatory requirement or a decrease in the ventilatory capacity, since either causes. a decrease in the breathing reserve (3) (usually the latter is the cause in chronic pulmonary emphysema) Bronchiolar narrowing is manifested clinically by thonchi and prolongation of expration

Obstructive emphysema is thus associated with the inability to expel air which 
leads to pıogressive aur trapping and alveolar over-distension. This is followed by rupture of alveoli, coalescence and bleb formation Destruction of elastic tissue also leads to collapse of bronchı on expiration which produces further air trap. ping and a vicious cycle. There is a gradual diminishing of available respira. tory exchange membrane Increase in the physiological dead space and eventual veno-arterial shunts occur and allow unoxygenated blood to pass into the arterial stream.

If all the known pulmonary function tests were carried out on a patient with advanced pulmonary emphysema (and some 50 individual tests are listed in reference works on this subject (5)), practically every value obtained would be abnormal, however, only certain principle observations will be made The lungs are distended even after a forced expiration The maximal expiratory flow rate is reduced so severely that effective coughing is impossible. Alveolar ventilation is slightly reduced, and the distribution of the inspired gas is very uneven. This results in anoxaemia, carbon dioxide retention and respiratory acidosis. Reduction in the pulmonary vascular bed also results in a decreased surface for gas exchange. The admmistration of bronchodilators does not improve vital capacity or flow rates as it does in simple asthma The mechanical difficultres are due in part to organic obstruction, but to a greater extent to check valves, which operate only durng expıration and lead to a large residual volume, slow expiration, and uneven ventilation The pulmonary insufficiency is caused by uneven alveolar ventılation ${ }_{\mathrm{a}} \mathrm{n}$ relation to pulmonary capıllary blood flow and to an inability to hyperventilate, for mechanical reasons-despite anoxaemia, increased arterial carbon dioxide tension, and low arterial $\mathrm{pH}$ Patients with emphysema usually hvperventilate until mechanıcal limitation becomes extreme

\section{Preoperative Management with Puldionary Emphysema}

A knowledge of the marked difficulties affecting both the respuratory apparatus per se and the blood-gas relationships must be considered when planning elective surgery for these patients The preparation for surgery in the presence of all but the most moderate degree of pulmonary emphysema must begin where possible well in advance of the proposed operation, as it does for patients with thyrotoxicosis This period of preparation should be as long as the patient continues to show improvement on medical management, and may be weeks or monthsbut modified by the imperativeness of the proposed surgery A series of measures can be undertaken to improve the patient's respiratory insufficiency. The objective is to bring the patient to the operation in a state where he can utilize his full respiratory reserve

Smoking should be prohibited A rigid programme of bronchial evacuation and bronchial dilation (22) should be instituted, with expectorants, bronchodilators, postural drainage and bronchoscopy being used if necessary. $\mathrm{V}_{\mathrm{I}}$ gorous treatment aganst bronchoconstriction by use of bronchodilator aersols with or without positive pressure inspiratory breathing should be used Other measures include the use of ephedrine or orthoxine-theophylline and aminophylline which can be given orally, intravenously, or rectally. Isuprel seems to be one of the better 
aerosol bronchodılators of the sympathommetic drugs. This drug in combination with Alevaire allows the patient to raise sputum with greater ease. The patient is instructed to completely and forcefully exhale before inhaling this mixture

The 1odides are still used as expectorant preparations A saturated solution of potassium lodide is generally given in dosage 8-15 drops three times a day. A combination of hydriodic acid with equal parts of oithoxime hydrochlonde also seems to work well as the orthoxine gives some bronchial relaxation.

Measures to correct cardiac complications should be instituted where necessary and should include the use of digitalıs, phlebotomy, aminophylline, mercurial diuretics, and sedation If phlebotomy, 1 s considered, not more than $350 \mathrm{cc}$ should be removed, keeping the haematocrit reading at 50 per cent. The mercurial diuretics must be used carefully to avoid a too rapid dehydration with a loss of the electrolytes. Recently Diamox, which is a synthetic diuretic, has been suggested in the treatment of chronic pulmonary emphysema. This drug acts by inhibition of carbonic anhydrase Pdtents receiving Diamox therapy showed a decrease in the carbon dioxide combining power with an increased exercise tolerance, a decreased dyspnoea, and an improvement in the performance of pulmonary function tests The dosage was given orally every eight hours, in a total darly dose of $10 \mathrm{mg} / \mathrm{kg}$. of body weight.

An oral aminophylline preparation used four times darly also produces good results. It is of special benefit in the cor pulmonale complications, It increases cardiac work and output by lowering peripheral resistance, especially in the pulmonary circulation, and dimmishes right arterial pressure It also dilates the bronchial tree and helps to promote diuresis.

Where infection is a complication, the proper antibiotics should be used at once The antibiotic can be used as an aersol either alone or in combination with Isuprel and Alevaire. If the organism is sensitive to penicllin, a higher concentration of the drug in the sputum can be obtained by use of Neo-Penil

Oxygen in low concentration can be used as stated before. However a recent pulmonary haemorrhage or spontaneous pneumothorax is considered an absolute contraindication to intermittent positive pressure breathing.

Patients with chronic pulmonary emphysema and intractable bronchial asthma who do not respond to the above procedures should be given corticotropin and/ or cortisone, even if there is chronic cor pulmonale. The presence of peptic ulcer or active pulmonary tuberculosis is a contraindication.

Pneumoperitoneum has been recommended by many in the treatment of chronic pulmonary emphysema $(1,3)$, and there has been much discussion pro and con as to its efficacy. Recently Beck (8) and his group suggested venous pressure as a guide. If the venous pressure rose, they advised the discontinuance of this treatment. If it dropped or showed no change, they considered it a good indication of effectiveness.

Breathing exercises should be taught to all patients with emphysema Efforts should be made to re-establish the excursions of the diaphragm. Having the patient use the abdominal muscles in breathing will bring this about (3)

Mechanical respirators may be of benefit $(23,24)$, either alone or with oxygen, or with bronchodilators and detergents. The benefits of the inspiratory positive 
pressure breathing are: $(a)$ impiovement in distribution of inspired air, $(b)$ all available alveoli are opened; $(c)$ reduction of the bronchial resistance yrelds more rapid air movement; $(d)$ reduction in the volume of residual air.

Premedication should aim at obtaining and maintaming bronchial relaxation. Therefore the evening and morning orders should make provision for a bronchodilator (aminophylline per rectum), and nebulization of epinephrine or Isuprel Preoperative sedation is best obtained with small amounts of Demerol and atropine. Since these patients are notoriously intolerant to morphine, none should be given

If morphine has been given, the antagonist Nalline should be given at once. Before this drug became avallable, the treatment of respiratory depression following the use of narcotıc agents was supportıve and symptomatic Nallne has a specific action which counteracts the respiratory depression from narcotic agents. In itself, Nalline is a respiratory depressant even in small doses. However, in the narcotized patient Nalline was found to be effective in overcoming the respiratory depression and even to stımulate respiration As well as being a morphine antagonist it counteracts the effect of Methadon, Metapon, Dilaudid, codeme, and Demerol and other related groups. The effect of Nalline on coma and circulatory, disturbances has been variable. Administration of 5-10 mg. of Nalline intravenously counteracts the respiratory depression n 15 to 30 seconds and other effects are counteracted in a somewhat longer pe:iod. If a continual effect is required, it is better to use $10 \mathrm{mg}$. of Nalline $\mathrm{m}$. $300-500 \mathrm{cc}$ of a 5 per cent dextrose in water solution given by a slow intravenous drip Nalline has no effect, even in large doses, on barbiturate intoxication (3).

\section{Conduct of Anaesthesta in Chronic Pulmonary Emphysema}

A study of 122 cases of pulmonary emphysema was reported by Cournand and Richards in 1949 (9). In this study they were able to divide the subjects into two large groups. Group 1, uncomplicated pulmonary insufficiency; Group 2, combined cardio-pulmonary insufficiency The patients, in Group 1 were further divided into three sub-groups, according to severity of ventlatory insufficiency and changes in arterial partial pressures of oxygen, carbon dioxide, and blood $\mathrm{pH}$. A standard test for exercrse tolerance was used for all patients. This classification or one similar would be useful in assessing the anaesthetic risk in these patients. It provides a knowledge of imparment of breathing reserve as well as of disturbances in blood-gas relationships.

If the operation can be accomplished with a low spinal anaesthetic which does not interfere with the tidal volume of the patient, then this is probably the anaesthetic of choice. Under these crrcumstances the patient gets rid of his own carbon dioxide and breathes 21 per cent oxygen or room air. The patient is conscious and therefore his co-operation can be ganned in the use of inspiratory positive pressure breathing.

If the operation is to be done in the upper abdomen, a spinal anaesthetic can be used but may interfere with tidal volume and produce a carbon dioxide mtoxication syndrome. This can be somewhat avoided by allowing the patient 
to breathe a nitrous-oxıde-oxygen mixture 70 per cent-30 per cent through sodalime on a partial re-breathing system By this means the respiration can be assisted but not controlled to maintain a normal tidal volume and prevent carbon dioxide accumulation The partial pressure of carbon dioxide of the blood which is usually elevated is mantaned as constant as possible, and the percentage of oxygen delivered to the alveol is not in too great excess of atmospheric cond1tions. The hypoxic drive is altered as little as possible if at all Even though some of the accessory muscles of respiration are ummobilized. it is suggested that effect is no more adverse than would be that of nitrous oxide and relaxant drugs

The foregoing remarks on spinal anaesthesıa apply to peridural anaesthesia as well except that the latter probably affords less muscular relaxation

Primary consideration should always be given to the feasibility of conduction or regional anaesthesia in patients with chronc pulmonary emphysema, especially in those in Group 2 (cardiac insufficiency) Tolerance of this type of procedure should not be very different from that found in the normal individual

If a general anaesthetic is selected, the best management should entail the use of a minimal quantity of Pentothal or Surtal for induction The administration of nitrous oxide--oxygen is then begun with oxygen concentrations not exceeding 30 per cent This method is advocated by Bodell who further suggests the use of Anectine or Brevidil as a drip for two purposes first, to simplify, endotracheal intubation, and secondly to secure adequate muscular relaxation Intubation should be mandatory to faclitate suctioning in these patients The use of these agents in conjunction with properly assisted respirations should prevent the development of carbon dioxide intoxication and its sequelae $(10,11)$

There will be a group of patients who manifest carbon dioxide retention preoperatively It has been suggested that these patients maght do well with an elective tracheotomy performed before they leave the table (10) The tracheotomy will facilitate suctioning and therefore the prevention of atelectasis Also, the tracheotomy effects a reduction in the dead space by some 150-200 cc Since these patients have a problem in distribution of their tidal volume, the reduced dead space results in more effective alveolar ventilation

The following attributes of nitrous oxide fortify the arguments for its use under these circumstances (a) The drug has specific anaesthetic properties ( $b$ ) Its prompt elimination from the body leads to rapid recovery from anaesthesia (spontaneous breathing-unassisted) (c) Its use is followed by munmal evidence of generalized post-anaesthesia depression (d) It causes no specific toxic effects on the myocardium, lung, liver, kidney, medulla or adrenals $(e)$ There is less stimulation of mucous secretions $(f)$ There is less nausea and vomiting (g) There is no loss of hypoxic druve-if oxygen concentration does not exceed 30 per cent ( $h$ ) Spontaneous respirations are possible ( $i)$ There is less carbon dioxide accumulation since N R B or PRB techniques can be used In short, the use of this agent causes the least interference with physiological processes in chronic pulmonary emphysema The Brevidil or Anectine drip is used because it should be easily controlled and quickly dissipated.

Much has been written on the question of controlled versus spontaneous 
respiration during anaesthesia in the presence of chronic pulmonary emphysema $(13,14,15,16)$. Michael Johnstone considers this disease a definite contraind1cation to controlled respiration in the unconscious patient One of the dangers stressed is the rupture of a sub-pleural bulla, with formation of a tension pneumothorax. The bullae are easy to inflate but difficult to deflate because of expiratory obstruction and arr trapping A case of successful deflation after controlled respiration has been accomplished by manual compression after opening the chest (17).

Increased intrapulmonary pressure may arrest the flow of blood through the lungs, resulting in the collapse of the systemic circulation. Fully anaesthetized and curarized patients who are supine with normal cardiovascular and respiratory systems tolerate well an intermittent intrapulmonary pressure of $10 \mathrm{~mm}$ $\mathrm{Hg}-15 \mathrm{~mm} \mathrm{Hg}$. Pressures in excess of $15 \mathrm{~mm} \mathrm{Hg}$ are sometimes followed by profound drops in the systemic pressure Patients with fixation of the thoracic cage and diminished pulmonary elasticity are particularly sensitive to pressures above $10 \mathrm{~mm} . \mathrm{Hg}$ ( 16 )

Contmuous y raised intrapulmonary pressure causes an increase in venous pressure of between 40 and 70 per cent of intra-mask pressure, thus positive pressure ventilation can result in increased capillary and venous haemorrhage unless care is taken This factor becomes more serious where vascular areas are concerned such as in the brain, spinal cord, and pelvic viscera, and may produce shock in excess of blood loss Thus Michael Johnstone states that the technique of completely controlled respiration is suitable only to thoracic and abdominal surgery, and is certainly to be avolded in the presence of ganglionic blockade, systemic hypotension, or shock (16)

The introduction of mechanical respirators which create a negative pressure phase durnng expiration may facilitate the safer ventilation of these curarized emphysematous patients, but opinions vary. The machines will not eliminate the need for relatively high inflationary pressures in emphysema

In the present state of our knowledge it is perhaps safest to use an anaesthetic technique which permits spontaneous respiration while providing adequate relaxation Auld (13) support the views of Michael Johnstone on the question of controlled versus spontanecius respiration.

Cyclopropane anaesthesia is not favoured for two principle reasons. (1) the concentration of oxygen employed is too high, and (2) many of these patients have received bronchodılator amines.

With ether anaesthesia the emergence is prolonged and the accumulation of secretions is greater Again the concentration of oxygen employed can be too high

\section{Postoperative Management}

The problems of postoperative management are incieased many tımes with patients suffering from chronic respiratory disease The usual problems of upper respiratory obstruction from the relaxed jaw, laryngospasm, laryngeal oedema, etc., are the same as found elsewhere of the more important problems the mherent secretions in the lower tracheo-bronchial tree present an increased 
hazard with chronic pulmonary emphysema, as well as with tuberculosis, bronchiectasis, and asthma, especially when the patient is unable to cough adequately because of' sedation or pam. The treatment of such conditions begms during the operation by means of frequent aspiration with long urethral catheters inserted well down into the tracheo-bronchial passages (18). Postoperatively urethral catheters passed blindly through the nose into the trachea will produce coughing and allow aspiration of secretions Occasionally bronchoscopic aspiration may be necessary or it may be well to make a routine of passing a bronchoscope at conclusion of operations on these patients. If secretions are extremely viscous and are interfering with oxygenation, it may be necessary to do a tracheotomy for reasons already outlined.

Lower respiratory obstruction is apt to occur with its attendant acute interference with alyeolar exchange. Atelectasis and tension pneumothorax have both been mentioned. Pulmonary oedema may occur as a result of excessive parenteral fluid durng operation or from too great a strain on the right heart and pulmonary hypertension.

Depression of the respiratory centre is usually the result of narcotics, barbiturates, or too deep anaesthesia Here foresight is better than indsight This applies equally well to the overzealous use of relaxant drugs.

Alterations in oxygen and carbon dioxide tensions are easily produced and if the stimulus to respiration is lost on this account, the patent may fail to breathe adequately for one or several hours in the postoperative period (13). Respirations can be supplemented, but care should be taken not to over-oxygenate the blood stream.

\section{SUMMARY}

An attempt has been made to review the pertinent literature on the subject of chronic pulmonary emphysema where it may have some bearing on the practice of anaesthesia Some dogmatic statements may have been made concerning procedures and techniques, particularly on the problem of anaesthetic management, but these by no means constitute the perfect solution to this serious problem. In addition to a knowledge of normal pulmonary physıology and function tests, the anaesthetist should be well aware of the abnormal physiology and altered function tests which are a part of this disease Pulmonary function studies should perhaps be used more frequently along with a basis of classification for severity of disease The anaesthetrc risk would then be more easily computed and the optimum anaesthetic management would then follow

\section{REFERENCES}

1 Carter, M G, Gaesslef, E A, \& Kyllonen, A. Pneumoperitoneum in the Treatment of Pulmonary Emphysema New England J Med 243 549-558 (1950)

2 Boyd, William. A Textbook of Pathology Phladelphia Lea \& Febiger (1943), pp. $445-447$

3 Poxonny, C The Pre-operative Management of the Patient with Chronic Respiratory Disease Current Researches in Anesth \& Analg 3.5 260-273 (1956) 
4 Segal, M S, \& Dulfalso, M J Chronic Pulmonary Emphysema. Modern Medical Monographs Green \& Stratton (1953)

5 Comroe, Forster, Dubors, Briscoe, Cardsen The Lung Chrago Yearbook Publishers (1951)

6 Motley, H L The Use of Pulmonary Function Tests with Special Reference to Anaesthesia. Current Researches in Anesth \& Analg 34 281-289 (1955)

7. Miller, W. F, Wu, Nancy, \& Johnson, R L; Jr Converuent Method of Evaluating Pulmonary Ventlatory Function with a Single-Breath Test Anaesthesiology 17 480493 (1956)

8 Beck, G J, Eastlake, A C, \& Barach, A L Venous Pressure as a Guide to Pneumoperitoneum Therapy in Pulmonary Emphysema Dis Chest 22 130-140 (1952)

9 Cournand, A, Ruchards, D W, Jr, \& Baldwin, E 'deF F'ulmonary Insufficiency III A Study of 122 cases of Pulmonary Emphysema Medicine 28 201 (1949)

10 Bonell, B, Anskro, F B., Blundell, A E Pulmonary Emphysema. A Method of Anaesthetic Management Current Researches in Anes \& Analg 35. 512-516 (1956)

11 Heller, M L, Nybofr, J, \& Storrs, R. C Nitrous Oxide-Oxygen-Curare Anaesthesia for the Geriatric Patient Current Researches in Anes \& Analg 34 121-150 (1955)

12 Harrus, J E A Physiological Test for Hypoxia in Nitrous Oxide Anaesthesia Current Researches in Anes \& A nalg 33 398-401 (1954).

13 Autd, W Emphysema and Controlled Respuation Anaesthesia 11. 263-264 (1956)

14 Mostert, J, W Emphysema and Controlled Respiration. Anaesthesia 10 410-411 (1955)

15 Johnsrone, $M$ Relaxants and the Human Cardio-Vascular System Anaesthesia 10155 (1955)

16 Johnstone, M Emphysema and Controlled Respiration Anaesthesia 11 165-167 (1956).

17 Chenshaw, iG L A M A, $156 \quad 1561$ (1954)

18 Stephen, C R Post-operative Management of the Patient with an Acute Respiratory Problem Curren: Researches in Anes \& Analg 35 320-3.30 (1956)

19 Beеr, E G Clin cal Evaluation of Pulmonary Function Tests Current Researches in Anes \& Analg $3.2 \quad 411-417$ (1953)

20 Woolf, C R Pulmonary Function Tests and Their Clinical Application. Canad M A J 75 (12). 1007-1015 (1956)

21 West, J. R, Baldwin, E deF, Lournand, A, \& Richards, D W Physiopathologic Aspects of Chromic Pulmonary Emphysema Am J Med 10 481-496 (1951).

22 Romagnol, A G F, \& BIRD, H M Post-operative Cough and the Prophylactic Use of Bronchodilators Canad M A I 75 (3). 210-212 (1956)

23 Affeldt, John E, Collier, Clarence R, \& Hackney, Jack D Mechanical Treatment of Pulmonary Fallure Postgrad Med 19 (6) · 550-558 (1956)

24 Stephen, C R, \& Fabian, L W Respiratory Resuscitation Postgrad Med 20 (1) 2-7 (1956).

25. KAVAN, E M \& \& HADDY, F J A Study of the Mechanics of Respiration in the Human Lung Prelmminary Report Current Researches in Anes \& Analg 35 343-349 (1956)

26. Feffer, James J, \& Mans, Jantes P Physiologic Basis for Rational Therapy in Chromic Pulmonary Emphysema Postgrad Med 19 (4) 332-340 (1946)

27. Maloney, J. V, Jr, Defrrick, W. S A Method for the Measurement of Pulmonary Ventilation during Anaesthesia Anesthesiology 13 571-576 (1952)

28 Cullen, S , G, Compoe, J H, et at Problems in Ventilation A Panel Discussion Anesthesiology $15 \quad 416-435$ (1954)

29 Woormen, $\mathrm{R}$ The Management of Respiratory Insufficiency Anaesthesia 11 281-288 (1956)

30 Mrles, $G$ G, Martin, $N$ T' \& Adriani, John Factors Influencing the Elimination of Nitrogen Using Semiclosed Inhalers Anesthesiology 17 213-221 (1956).

31 Clappison, G B \& Hamilton, W K Respiratory Adjustments to Increases in External Dead Space. Anesthesiology 17 643-647 (1956). 
32 Rigler, Leo G X-Ray Diagnosis of Cancer of the Lung Postgrad Med 18 (5) 361373 (1955)

33 Editorials and Comments Body Position and the Mechanıcs of Breathing Canad M A J 75 (11) 938-939 (1956)

34 Hurley, G A P Pneumatocele Disease Canad M A T 74 (5) 356-360 (1956)

35 Best, C H, \& Taylon, $N^{\prime}$ B The Physiological Basis of Medical Practice Willams \& Wilkins (1943)

36. Walton, F A Bronchial Asthma and Anaesthesia Canat M A J 74 (8) 624-629 (1956)

37 Hewer, C L The Physiology and Complications of the Trendelenberg Position Canad M A J 74 (4) 285-288 (1956)

38 Editorials Anaesthetic Sequelae in the Elderly Canad M A J 73 (11) 903 (1955)

39 LeE, J. Alfred A Synopsis of Anaesthesia Third edition John Wright (1953)

40 Cournand, A Rrchards, D W, JR, \& Baldwin E deF Pulmonary Insufficiency, Physiological Classification, Clinical Methods of Analysis, Standard Values in Normal Subjects Medicine 27 243-278 (1948)

41 Fink, B R Diffusion Anoxıa Anesthesiology 16 511-519 (1955) 